\title{
Power System Restoration Assessment Indices computation for a Restructured Power System with Bacterial Foraging Optimized Load - Frequency Controller
}

\author{
R.Thirunavukarasu \\ Assistant Professor \\ Department of Electrical \\ Engineering \\ Annamalai University, \\ Annamalainagar \\ Tamilnadu, India.
}

\author{
B.Paramasivam \\ Assistant Professor \\ Department of Electrical \\ Engineering \\ Annamalai University, \\ Annamalainagar \\ Tamilnadu, India,
}

\author{
I.A. Chidambaram \\ Professor \\ Department of Electrical \\ Engineering \\ Annamalai University, \\ Annamalainagar \\ Tamilnadu, India,
}

\begin{abstract}
This paper proposes, various design procedures for computing Power System Restoration Assessment Indices (PSRAI) for a Two-Area Hydro-Thermal Reheat Interconnected Power System (TAHTRIPS) in a restructured environment with a loadfrequency controller optimized using Bacterial Foraging Optimization (BFO) algorithm. In the restructured scenario, as various types of apparatus with large capacity may enhance fast power consumption which causes serious problem in the frequency oscillations. The oscillation of system frequency may sustain and grow to cause stability problems in the system if no adequate damping is provided. The disturbances to the power system due to a small load change can even result in wide deviation in system frequency which is referred as load-frequency control problem. Quick system restoration is of prime importance not only based on the time of restoration and also stability limits also plays a very vital role in power system restoration problems due to unexpected load variations in power systems. The simple conventional Proportional plus Integral (PI) controllers are still popular in power industry for frequency regulation as in case of any change in system operating conditions new gain values can be computed easily even for multi-area power systems. This paper focus on the computation of various PSRAI for TAH(with mechanical governor) -TRIPS and TAH (with Electric governor)- TRIPS unit based on the settling time concept, The design of the Proportional plus Integral (PI) controller gains are tuned using Bacterial Foraging Optimization (BFO) algorithm. These controllers are implemented to achieve a fast restoration time in the output responses of the system when the system experiences with various step load perturbations. In this paper the PRSAI are calculated for different types of possible transactions and the necessary remedial measures to be adopted are also suggested.
\end{abstract}

\section{Keywords}

Bacterial Foraging Optimization, Electric Governor, LoadFrequency Control, Proportional plus Integral Controller, Restructured Power System, Power System Restoration Assessment Indices.

\section{INTRODUCTION}

The electric power business at present is largely in the hands of Vertically Integrated Utilities (VIU) which own generation, transmission and distribution systems that supply power to the customer at regulated rates. The electric power can be bought and sold between the interconnected VIU through the tie-lines and moreover such interconnection should provide greater reliability [1]. The major change that had happened is with the emergence of Independent Power Producer (IPP) that can sell power to VIU. In the restructure environment it is generally agreed that the first step is to separate the generation of power from the transmission and distribution companies, thus putting all the generation on the same footing as the IPP [2]. In an interconnected power system, a sudden load perturbation in any area causes the deviation of frequencies of all the areas and also in the tie-line powers. This has to be corrected to ensure the generation and distribution of electric power companies to ensure good quality. This can be achieved by optimally tuning Load-Frequency controller gains. Many investigations in the area of Load-Frequency Control (LFC) problem for the interconnected power systems have been reported over the past six decades. A number of control strategies have been employed in the design of load-frequency controllers in order to achieve better dynamic performance. The efficient incorporation of controllers will modify the transient response and steady state error of the system. Among the various types of load-frequency controllers, the most widely employed is the conventional Proportional plus Integral controller (PI). A lot of studies have been made related to LFC in a deregulated environment over last decades. These studies try to modify the conventional LFC system to take into account the effect of bilateral contracts on the dynamics [3] and improve the dynamical transient response of the system [4-7] under various operating conditions. With the restructured electric utilities, the Load-Frequency Control requirements especially the nominal frequency in an interconnected power system besides maintaining the net interchange of power between control areas at predetermined values should be enhanced to ensure the quality of the power 
system. The importance of decentralized controllers for multi area load-frequency control in the restructured environment, where in, each area controller uses only the local states for feedback, is well known. The stabilization of frequency oscillations in an interconnected power system becomes challenging when implemented in the future competitive environment. So advanced economic, high efficiency and improved control schemes $[8,9]$ are required to ensure the power system reliability for which PSRAI can be used as a tool. In this paper various methodologies were adopted in computing Power System Restoration Assessment Indices (PSRAI) for Two-Area Hydro (with Mechanical/Electrical governor) Thermal Reheat Interconnected Power System (TAHTRIPS) in a restructured environment. With the various Power System Restoration Assessment Indices (Feasible Restoration Indices, Comprehensive Restoration Indices) the remedial measures to be taken can be adjudged like integration of additional spinning reserve, incorporation of effective intelligent controllers, load shedding etc.

In the early stages of power system restoration, the black start units are of the greatest interest because they will produce power for the auxiliaries of the thermal units without black start capabilities [9]. Under this situation a conventional frequency control i.e., a governor may no longer be able to compensate for sudden load changes due to its slow response. Therefore, in an inter area mode, damping out the critical electromechanical oscillations is to be carried out effectively in the restructured power system. Moreover, system frequency deviations should be monitored and remedial actions to overcome the frequency excursions are more likely to protect the system before it enters an emergency mode of operation. The restoration process of the bulk-power transmission system following a partial or a total blackout has two main issues during a restoration; these are voltage control and frequency control [10]. Special attention is therefore given to the behavior of network parameters, control equipments as they affect the voltage and frequency regulation during the restoration process which in turn reflects in PSRAI. During restoration due to wide fluctuations in the frequency and voltage it becomes very difficult to maintain the integrity in the system. Inability to control the frequency may lead to unsuccessful restoration. The repeated collapse of the system Islands due to tripping of generators due to either over frequency or under frequency condition causes delay in getting normalcy [10]

Now-a-days the complexities in the power system are being solved with the use of Evolutionary Computation (EC) such as Differential Evolution (DE) [11], Genetic Algorithms (GA), Practical Swarm Optimizations (PSO) [12] and Ant Colony Optimization (ACO) [13], which are some of the heuristic techniques having immense capability of determining global optimum. Classical approach based optimization for controller gains is a trial and error method and extremely time consuming when several parameters have to be optimized simultaneously and provides suboptimal result. Some authors have applied GA to optimize the controller gains more efficiently, but the premature convergence of GA degrades its search capability [14]. Recent research has brought out some deficiencies in using GA, PSO based techniques $[14,15]$. The Bacterial Foraging Optimization [BFO] mimics how bacteria forage over a landscape of nutrients to perform parallel non gradient optimization [16]. The BFO algorithm is a computational intelligence based technique that is not affected larger by the size and nonlinearity of the problem and can be convergence to the optimal solution in many problems where most analytical methods fail to converge. This more recent and powerful evolutionary computational technique BFO [16] is found to be user friendly and is adopted for simultaneous optimization of several parameters for both primary and secondary control loops of the governor.

To obtain the best convergence performance, an effective cost function is derived using the tie-line power and frequency deviations of the control areas and their rates of changes according to time integral. The main function of LFC is to regulate a signal called Area Control Error (ACE), which accounts for error in the frequency as well as the errors in the interchange power with neighboring areas. Conventional LoadFrequency Control uses a feedback signal that is either based on the Integral of ACE or is based on ACE and it's Integral. These feedback signals are used to maneuver the turbine governor set points of the generators so that the generated power follows the load fluctuations, however continuously tracking load fluctuations definitely causes wear and tear on governor's equipment, shortens their lifetime, and thus requires replacing them, which can be very costly. In this study, BFO algorithm is used to optimizing the Proportional plus Integral (PI) controller gains for the load frequency control of a Two-Area HydroThermal Reheat Interconnected Power System (TAHTRIPS) in a restructured environment. Various case studies are analyzed to develop Power System Restoration Assessment Indices (PSRAI) namely, Feasible Restoration Index (FRI) and Complete Restoration Index (CRI) which are able to predict the normal operating mode, emergency mode and restorative modes of the power system.

\section{MODELING OF A TWO-AREA HYDRO- THERMAL REHEAT INTERCONNECTED POWER SYSTEM (TAHTRIPS) IN RESTRUCTURED}

Load-Frequency Control (LFC) plays a very important role in power system and its main role is to maintain loadgeneration balance. Many investigations in the field of LFC for an interconnected system have been reported in literature over past few decades, which emphasizes on LFC pertaining to a thermal system and relatively a lesser attention has been contributed towards the LFC of a Hydro-Thermal system of widely different characteristics [17-22]. In this paper, investigation has been carried out for a TAHTIPS in which small perturbations was made to occur in area-1 and in area-2 and their impact on optimum selection of controller gain settling has been assessed based on the various Restoration Indices.

In the restructured competitive environment of power system, the Vertically Integrated Utility (VIU) no longer exists. The deregulated power system consists of GENCOs, DISCOs, and Transmissions Companies (TRANSCOs) and Independent System Operator (ISO). GENCOs which will compete in a free market to sell the electricity they produce. Mostly the retail customer will continue for some time to buy from the local distribution company and distribution companies have been designated as DISCOs. The entities that will wheel this power between GENCOs and DISCOs have been designated as TRANSCOs. Although it is conceptually clean to have separate functionalities for the GENCOs, TRANSCOs and DISCOs, in 
reality there will exist companies with combined or partial responsibilities. With the emergence of the distinct identities of GENCOs, TRANSCOs, DISCOs and the ISO, many of the ancillary services of a VIU will have a different role to play and hence have to be modeled differently. Among these ancillary service controls one of the most important services to be enhanced is the Load-frequency control [23]. The LFC in a deregulated electricity market should be designed to consider different types of possible transactions, such as poolco-based transactions, bilateral transactions and a combination of these two [24]. In the new scenario, a DISCO can contract individually with a GENCO for acquiring the power and these transactions will be made under the supervision of ISO. To make the visualization of contracts easier, the concept of "DISCO Participation Matrix" (DPM) is used which essentially provides the information about the participation of a DISCO in contract with a GENCO. In DPM, the number of rows has to be equal to the number of GENCOs and the number of columns has to be equal to the number of DISCOs in the system. Any entry of this matrix is a fraction of total load power contracted by a DISCO toward a GENCO. As a results total of entries of column belong to DISCOi of DPM is $\sum_{i} c p f_{i j}=1$. In this study twoarea interconnected power system in which each area has two GENCOs and two DISCOs. Let GENCO 1, GENCO 2, DISCO 1, DISCO 2 be in area 1 and GENCO 3, GENCO 4, DISCO 3, DISCO 4 be in area 2 as shown in Fig 1.The corresponding DPM is given as follows

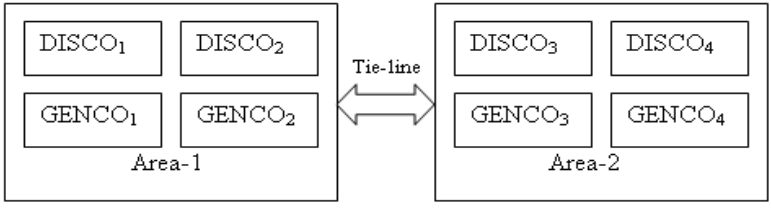

Fig .1 Schematic diagram of two-area system in restructured environment

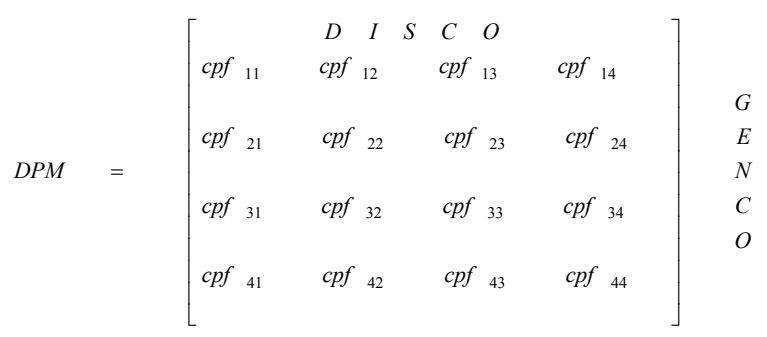

Where $c p f$ represents "Contract Participation Factor" and is like signals that carry information as to which the GENCO has to follow the load demanded by the DISCO. The linearized model of a two-area Hydro- Thermal reheat interconnected power system in deregulated environment is shown in Fig.2. The actual and scheduled steady state power flow through the tieline is given as

$$
\begin{aligned}
\Delta P_{\text {tiel-2, scheduled }} & =\sum_{i=1}^{2} \sum_{j=3}^{4} c p f_{i j} \Delta P_{L j}-\sum_{i=3}^{4} \sum_{j=1}^{2} c p f_{i j} \Delta P_{L j} \\
\Delta P_{\text {tie } 1-2, \text { actual }} & =\left(2 \pi T_{12} / s\right)\left(\Delta F_{1}-\Delta F_{2}\right)
\end{aligned}
$$

And at any given time, the tie-line power error $\Delta P_{\text {tiel-2, error }}$ is defined as

$\Delta P_{\text {tie1-2, error }}=\Delta P_{\text {tie1-2, actual }} \quad-\Delta P_{\text {tiel-2, scheduled }}$

The error signal is used to generate the respective ACE signals as in the traditional scenario [6]

$$
\begin{aligned}
& A C E_{1}=\beta_{1} \Delta F_{1}+\Delta P_{\text {tie } 1-2, \text { error }} \\
& A C E_{2}=\beta_{2} \Delta F_{2}+\Delta P_{\text {tie } 2-1, \text { error }}
\end{aligned}
$$

For two area system as shown in Fig.1, the contracted power supplied by $i^{\text {th }}$ GENCO is given as

$$
\Delta P g_{i}=\sum_{j=1}^{D I S C O}=4 f_{i j} \Delta P L_{j}
$$

Also note that $\triangle P L_{1, L O C}=\triangle P L_{1}+\triangle P L_{2}$ and $\triangle P L_{2, L O C}=\triangle P L_{3}+\triangle P L_{4}$. In the proposed LFC implementation, contracted load is fed forward through the DPM matrix to GENCO set points. The actual loads affect system dynamics via the input $\triangle P L_{, L O C}$ to the power system

blocks. Any mismatch between actual and contracted demands will result in frequency deviations that will drive LFC to re dispatch the GENCOs according to ACE participation factors, i.e., $\operatorname{apf}_{11}, \operatorname{apf}_{12}, \operatorname{apf}_{21}$ and $\operatorname{apf}_{22}$. The state space representation of the minimum realization model of ' $N$ ' area interconnected power system may be expressed as [25].

$$
\begin{aligned}
& \dot{x}=\mathrm{A} x+\mathrm{B} u+\Gamma d \\
& y=C x
\end{aligned}
$$

Where $\mathrm{X}=\left[\mathrm{x}_{1}^{\mathrm{T}}, \Delta \mathrm{p}_{\mathrm{ei}} \ldots \mathrm{x}_{(\mathrm{N}-1)}^{\mathrm{T}}, \Delta \mathrm{p}_{\mathrm{e}(\mathrm{N}-1)} \ldots \mathrm{x}_{\mathrm{N}}^{\mathrm{T}}\right]^{\mathrm{T}}, n$ - state vector

$$
n=\sum_{i=1}^{N} n_{i}+(N-1)
$$

$u=\left[u_{1}, \ldots u_{N}\right]^{T}=\left[\Delta P_{C 1} \ldots P_{C N}\right]^{T}, N$ - Control input vector $d=\left[d_{1}, \ldots d_{N}\right]^{T}=\left[\Delta P_{D 1} \ldots P_{D N}\right]^{T}, N$ - Disturbance input vector $y=\left[y_{1} \ldots y_{N}\right]^{T}, 2 N-\quad$ Measurable output vector where $A$ is system matrix, $B$ is the input distribution matrix, $\Gamma$ is the disturbance distribution matrix, $C$ is the control output distribution matrix, $\mathrm{x}$ is the state vector, $u$ is the control vector and $d$ is the disturbance vector consisting of load changes.

As stated earlier, in the Hydro power plan, the electric governor operation is very fast in nature than that of the system used with mechanical governors as the speed sensing, droop compensation and computing functions are performed electrically. The output signal drives electro-mechanical transducer, which operates a pilot valve and pilot valve servo motor. The turbine rotor speed is measured electronically with high accuracy [23]. And, here in this case study it is used as a feedback controller which drives the plant to be controlled within a weighted sum of error and integral of that value i.e. it produces an output signal consisting of two terms one proportional to error signal and the other proportional to integral of error signal. 


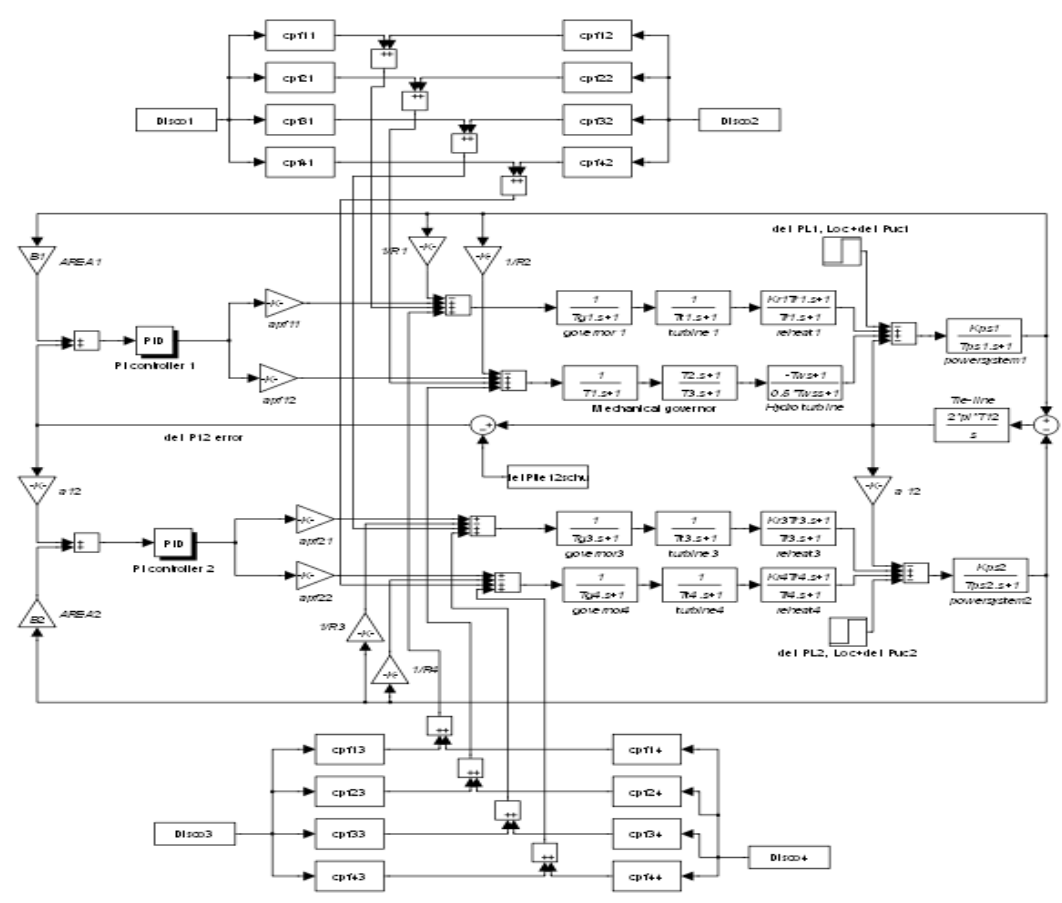

Fig. 2 Linerized model of a two-area hydro-Thermal reheat interconnected power system in restructured environment

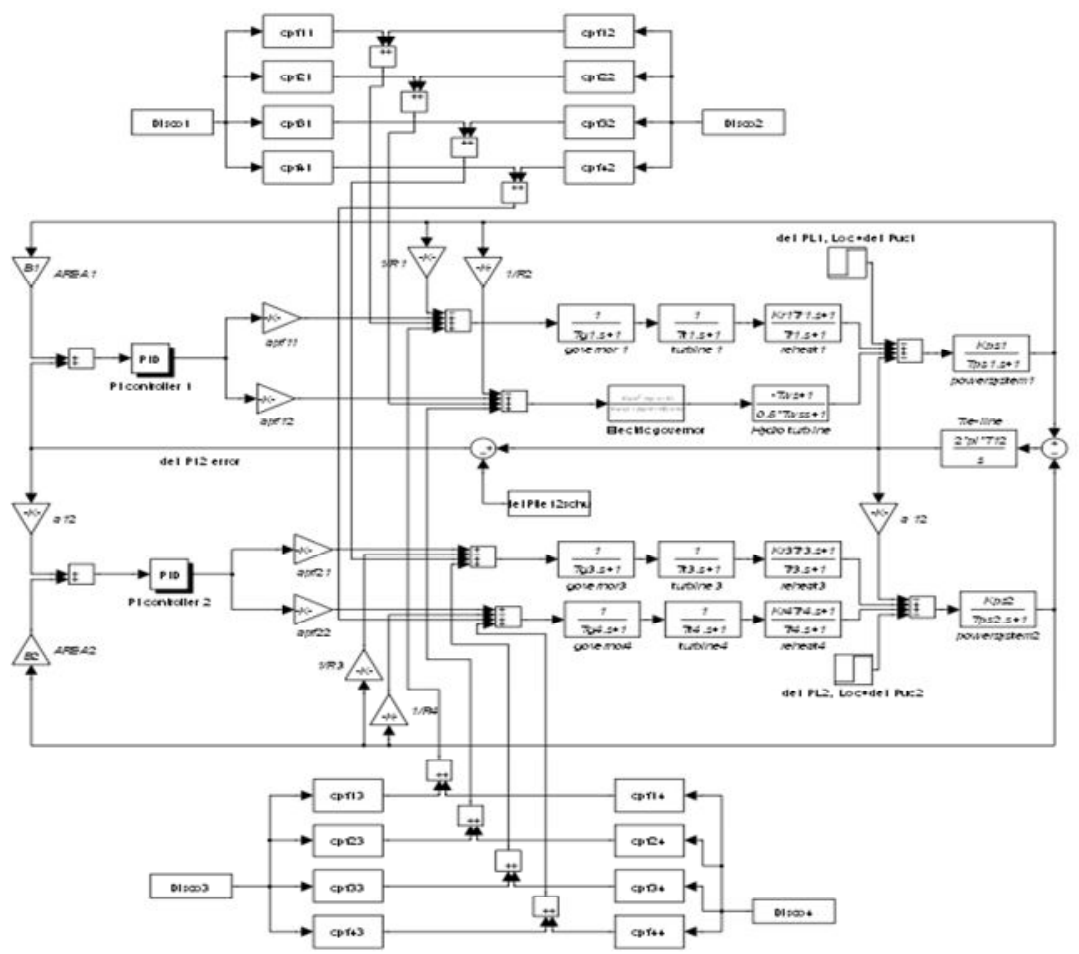

Fig. 3 Linerized model of a two-area hydro (with electric governor) thermal reheat interconnected power system in restructured environment 


\section{DESIGN OF DECENTRALIZED PI CONTROLLERS}

The proportional plus Integral controller gain values are tuned based on the cost function time of the output response of the system (especially the frequency deviation) and with these gain values the performance of the system is analyzed and the PSRAI are computed. In this case study the feedback controller adopted drives the plant to be controlled within a weighted sum of error and integral of that value i.e. it produces an output signal consisting of two terms one proportional to error signal and the other proportional to integral of error signal. The Integral Square Error (ISE) criterion [20] is used as the objective function and minimized using Bacterial Foraging Optimization Technique by effectively tunning the Proportional plus Integral gains $\left(\mathrm{K}_{\mathrm{Pi}}, \mathrm{K}_{\mathrm{Ii}}\right)$ in the LFC loop.

Where,

$$
\begin{gathered}
U_{1}=-K_{p} A C E_{1}-K_{I} \int A C E_{1} d t \\
U_{2}=-K_{p} A C E_{2}-K_{I} \int A C E_{2} d t
\end{gathered}
$$

Where, $K_{p}$ - Proportional gain, $K_{I}$ - Integral gain, $A C E$ - Area Control Error, $U_{1}, U_{2}$ - Control input requirement of the respective areas. The relative simplicity of this controller is a successful approach towards the zero steady state error in the frequency of the system.

\section{BACTERIAL FORAGING OPTIMIZATION (BFO) TECHNIQUE}

\subsection{Review of Bacterial Foraging Optimization}

The BFO method was introduced by Possino [16] motivated by the natural selection which tends to eliminate the animals with poor foraging strategies and favor those having successful foraging strategies. The foraging strategy is governed by four processes namely Chemotaxis, Swarming, Reproduction and Elimination and Dispersal. Chemotaxis process is the characteristics of movement of bacteria in search of food and consists of two processes namely swimming and tumbling. A bacterium is said to be swimming if it moves in a predefined direction, and tumbling if it starts moving in an altogether different direction. To represent a tumble, a unit length random direction $\phi(j)$ is generated. Let, " $j "$ is the index of chemotactic step, " $k$ " is reproduction step and " $l$ " is the elimination dispersal event. $\theta_{i}(j, k, l)$, is the position of $i^{\text {th }}$ bacteria at $j^{\text {th }}$ chemotactic step $k^{\text {th }}$ reproduction step and $l^{\text {th }}$ elimination dispersal event. The position of the bacteria in the next chemotatic step after a tumble is given by

$$
\theta^{i}(j+1, \quad k, l)=\theta^{i}(j, \quad k, l)+C(i) \phi(j)
$$

If the health of the bacteria improves after the tumble, the bacteria will continue to swim to the same direction for the specified steps or until the health degrades. Bacteria exhibits swarm behavior i.e. healthy bacteria try to attract other bacterium so that together they reach the desired location (solution point) more rapidly. The effect of swarming [19] is to make the bacteria congregate into groups and moves as concentric patterns with high bacterial density. Mathematically swarming behavior can be modeled

$$
\begin{aligned}
J_{c c}(\theta, P(j, k, l)) & =\sum_{i=1}^{S} J^{i} c c\left(\theta, \theta^{i}(j . k . l)\right) \\
& =\sum_{i=1}^{S}\left[-d_{\text {attract }} \exp \left(-\omega_{\text {attract }}\right) \sum_{m=1}^{p}\left(\theta^{m}-\theta_{m}^{i}\right)^{2}\right] \\
& +\sum_{i=1}^{S}\left[-h_{\text {repelent }} \exp \left(-w_{\text {repelent }}\right) \sum_{m=1}^{p}\left(\theta^{m}-\theta_{m}^{i}\right)^{2}\right]
\end{aligned}
$$

Where

$J_{C C}$ - Relative distance of each bacterium from the fittest bacterium

$S \quad$ - Number of bacteria

$p \quad$ - Number of parameters to be optimized

$\theta^{m} \quad$ - Position of the fittest bacteria

$d_{\text {attract }}, \omega_{\text {attract }}, h_{\text {repelent }}, \omega_{\text {repelent }}$ - different co-efficients representing the swarming behavior of the bacteria which are to be chosen properly In Reproduction step, population members who have sufficient nutrients will reproduce and the least healthy bacteria will die. The healthier population replaces unhealthy bacteria which get eliminated owing to their poorer foraging abilities. This makes the population of bacteria constant in the evolution process. In this process a sudden unforeseen event may drastically alter the evolution and may cause the elimination and / or dispersion to a new environment. Elimination and dispersal helps in reducing the behavior of stagnation i.e., being trapped in a premature solution point or local optima.

\subsection{Bacterial Foraging Algorithm}

In case of BFO technique each bacterium is assigned with a set of variable to be optimized and are assigned with random values $[\Delta]$ within the universe of discourse defined through upper and lower limits between which the optimum value is likely to fall. In the proposed method of proportional plus integral gain $\left(\mathrm{K}_{\mathrm{Pi}}, \mathrm{K}_{\mathrm{I}} \mathrm{i}\right)(\mathrm{i}=1,2)$ scheduling, each bacterium is allowed to take all possible values within the range and the cost objective function which is represented by $\mathrm{Eq}$ (9) is minimized. In this study, the BFO algorithm reported in [25] is found to have better convergence characteristics and is implemented as follows.

Step -1 Initialization;

1. Number of parameter $(p)$ to be optimized.

2. Number of bacterial $(S)$ to be used for searching the total region.

3. Swimming length $(N s)$, after which tumbling of bacteria will be undertaken in a chemotactic loop

4. $N_{C}$ - the number of iteration to be undertaken in a chemotactic $\operatorname{loop}\left(N_{C}>N_{S}\right)$ 
5. $N_{r e}$ - the maximum number of reproduction to be undertaken. 6. $N_{\text {ed }}$ the maximum number of elimination and dispersal events to be imposed over bacteria

7. $P_{e d}$ - the probability with which the elimination and dispersal events will continue.

8. The location of each bacterium $P(1-p, 1-s, 1)$ which is specified by random numbers within

$[-1,1]$

9. The value of $C(i)$, which is assumed to be constant in this case for all bacteria to simplify the design strategy.

10 . The value of $d_{\text {attract, }} W_{\text {attract }}, h_{\text {repelent }}$ and $W_{\text {repelent. }}$ It is to be noted here that the value of $\quad d_{\text {attract }}$ and $h_{\text {repelent }}$ must be same so that the penalty imposed on the cost function through " $J_{C C}$ ", of Eq (14) will be " 0 " when all the bacteria will have same value, i.e. they have converged. After initialization of all the above variables, keeping one variable changing and others fixed the value of " $U$ " proposed in Eq (9) is obtained by running the simulation of system using the parameter contained in each bacterium. For the corresponding minimum cost, the magnitude of the changing variable is selected. Similar procedure is carried out for other variables keeping the already optimized one unchanged. In this way all the variables of step 1- initialization are obtain and are presented below

$S=6, N_{c}=10, N s=3, N_{r e}=15, N_{e d}=2, P_{e d}=0.25, d_{\text {attract }}$ $=0.01, w_{\text {atract }}=0.04, h_{\text {repelent }}=0.01$, and $w_{\text {repelent }}=10, p=2$.

Step - 2 Iterative algorithms for optimization:

This section models the bacterial population chemotaxis Swarming, reproduction, elimination, and dispersal (initially, $j=k=l=0$ ) for the algorithm updating $\theta^{i}$ automatically results in updating of ' $P$ '.

1. Elimination-dispersal loop: $l=l+1$

2. Reproduction loop: $k=k+1$

3. Chemotaxis loop: $j=j+1$

a) For $\mathrm{i}=1,2 \ldots S$, calculate cost for each bacterium $i$ as follows.

- $\quad$ Compute value of cost $J(i, j, k, l)$

- $\quad J_{s w}(i, j, k, l)=J(i, j, k, l)+J_{c c}\left(\theta^{i}(j, k, l), P(j, k, l)\right)$ [i.e., add on the cell to cell attractant effect obtained through Eq (43) for swarming behavior to obtain the cost value obtained through Eq (9)].

- Let $J_{\text {last }}=J_{s w}(i, j, k, l)$ to save this value since a better cost via a run be found.

- $\quad$ End of for loop.

b) for $i=1,2 \ldots . \mathrm{S}$ take the tumbling / swimming decision.

- Tumble: generate a random vector $\Delta(i) \in \mathfrak{R}^{p}$ with each element $\Delta_{m}(i) m=1,2, \ldots \ldots . . p, \quad$ a random number ranges from $[-1,1]$.

- Move the position the bacteria in the next chemotatic step after a tumble by Eq (10). Fixed step size in the direction of tumble for bacterium ' $i$ ' is considered

- Compute $J(i, j+1, k, l)$ and then let

$J_{s u}(i, j+1, k, l)=J(i, j+1, k, l)+J_{c c}(\theta(j+1, k, l), P(j+1, k, l))$
- Swim:

(i) Let $\mathrm{m}=0$; ( counter for swim length)

(ii) While $m<N s$ (have not climbed down too long)

- $\quad$ Let $m=m+1$

- If $J_{s w}(i, j+1, k, l)<J_{\text {last }}$ (if doing better), let $J_{\text {last }}=\mathrm{J}_{\mathrm{sw}}(i, j+1, k, l)$ and let

$\theta^{i}(j+1, \quad k, \quad l)=\theta^{i}(j, \quad k, \quad l)+C(i) \frac{\Delta(i)}{\sqrt{\Delta^{T}(i) \Delta(i)}}$ (13) Where $C(i)$ denotes step size; $\Delta(i)$ Random vector; $\Delta^{T}(i)$ Transpose of vector $\Delta(i)$.using Eq (13) the new $J(i, j+1, k, l)$ is computed. Else let $m=N_{s}$. This the end of while statement

c). Go to next bacterium $(i+1)$ is selected if $i \neq S$ (i.e. go to step- $b)$ to process the next bacterium

4. If $j<N_{c}$, go to step 3. In this case, chemotaxis is continued since the life of the bacteria is not over.

5. Reproduction

a). For the given $\mathrm{k}$ and $l$ for each $i=1,2 \ldots S$, let $J^{i}{ }_{\text {health }}=\min _{j \in\left\{1 \ldots N_{c}\right]}\left\{J_{s w}(i, j, k, l)\right\}$ be the health of the bacterium $i$ (a measure of how many nutrients it got over its life time and how successful it was in avoiding noxious substance). Sort bacteria in the order of ascending cost $J_{\text {health }}$ (higher cost means lower health).

b). when $\mathrm{S}_{\mathrm{r}}=\mathrm{S} / 2$ bacteria with highest $J_{\text {health }}$ values die and other $S_{r}$ bacteria with the best value split [and the copies that are placed at the same location as their parent].

6. If $k<N_{r e}$, go to 2 ; in this case, as the number of specified reproduction steps have not been reached, so the next generation in the chemotactic loop is to be started.

7. Elimination -dispersal: for $i=1,2 \ldots S$ with probability $P_{e d}$, eliminates and disperses each bacterium [this keeps the number of bacteria in the population constant] to a random location on the optimization domain.

\section{SIMULATIONS RESULT AND OBSERVATIONS}

The Two-Area Hydro-Thermal Interconnected Restructured Power System considered for the study consists of two GENCOs and two DISCOs in each area. In area 1 GENCO consists of one hydro unit (Mechanical/Electric governor) and one thermal reheat unit. In area 2 both GENCOS consist of thermal reheat units. The nominal parameters are given in Appendix. The optimal solution of control inputs is taken an optimization problem, and the cost function [25] is obtained using the frequency deviations of control areas and tie- line power changes. The Proportional plus Integral controller gains 
$\left(\mathrm{K}_{\mathrm{p}} \mathrm{K}_{\mathrm{i}}\right)$ are tuned with $\mathrm{BFO}$ algorithm by optimizing the solutions of control inputs for the various case studies as shown in Table 1. The results are obtained by MATLAB 7.01 software and 50 iterations are chosen for the convergence of the solution in the BFO algorithm. These PI controllers are implemented in a Two-Area Hydro-Thermal Interconnected restructured Power System for different type of transactions. The corresponding frequency deviations $\Delta f$, tie- line power deviation $\Delta \mathrm{P}_{\text {tie }}$ and control input deviations $\Delta \mathrm{P}_{\mathrm{c}}$ are obtained with respect to time as shown in figures 4-6. From the simulated results it is observed that the restoration process with the Hydro Turbines with Electric Governor ensures not only reliable operation but also provides a good margin of stability when compared with that of a Hydro plant with Mechanical Governor.

More over Power System Restoration Indices namely, Feasible Restoration Indices (FRI) when the system is operating in a normal condition with both units in operation and Comprehensive Restoration Indices (CRI) are one or more unit outage in any area are obtained as discussed. In this study GENCO-4 in area 2 is outage are considered. From these Restoration Indices the restorative measures like the magnitude of control input, rate of change of control input required can be adjudged.

\subsection{Feasible Restoration Indices}

\subsubsection{Scenario 1: Poolco based transaction}

The optimal Proportional plus Integral (PI) controller gains are obtained for TAHTIPS considering various case studies for framing the Feasible Restoration Indices (FRI) which were obtained based on Area Control Error (ACE) as follows:

Case 1: In the TAHTIPS considering Hydro (with Mechanical/Electrical governor)-Thermal (HT) unit in area-1 and Thermal-Thermal (TT) units in area-2, for Poolco based transaction: in which the GENCOs in each area participate equally in LFC.If the load change occurs only in area 1. It denotes that the load is demanded only by DISCO 1 and DISCO 2. Let the value of this load demand be 0.1 p.u MW for each of them i.e. $\Delta \mathrm{PL}_{1}=0.1$ p.u $\mathrm{MW}, \Delta \mathrm{PL}{ }_{2}=0.1$ p.u $\mathrm{MW}, \Delta \mathrm{PL}_{3}=$ $\Delta \mathrm{PL}_{4}=0.0$. DISCO Participation Matrix (DPM) referring to Eq (14) is considered as [25]

$$
D P M=\left[\begin{array}{cccc}
0.5 & 0.5 & 0 & 0 \\
0.5 & 0.5 & 0 & 0 \\
0 & 0 & 0 & 0 \\
0 & 0 & 0 & 0
\end{array}\right]
$$

Note that DISCO 3 and DISCO 4 do not demand power from any GENCOs and hence the corresponding contract participation factors (columns 3 and 4) are zero. DISCO 1 and DISCO 2 demand identically from their local GENCOs, viz., GENCO 1 and GENCO 2. Therefore, $\operatorname{cpf}_{11}=\operatorname{cpf}_{12}=0.5$ and $\mathrm{cpf}_{21}=\mathrm{cpf}_{22}=0.5$. The frequency deviations $(\Delta f)$ both area, tieline power deviation $\Delta \mathrm{P}_{\text {tie }}$ and control input deviations $\Delta \mathrm{P}_{\mathrm{c}}$ as shown the figure 4 . The settling time $\left(\varsigma_{S}\right)$ and peak over /under shoot $(M p)$ of frequency deviations $(\Delta f)$ in both the area and tieline power deviation $\Delta \mathrm{P}_{\text {tie }}$ were obtained from figures $4(\mathrm{a}), 4(\mathrm{~b})$ and 4(c). From these values Feasible Restoration Indices are calculated as follows.

Step 5.1; The Feasible Restoration Index $1\left(\varepsilon_{1}\right)$ is obtained from the ratio between the settling time of frequency deviation in area $1\left(\varsigma_{s 1}\right)$ and power system time constant $\left(T_{p 1}\right)$ of area 1

$$
F R I_{1}=\frac{\varsigma_{s 1}}{T_{p 1}}
$$

Step 5.2; The Feasible Restoration Index $2\left(\varepsilon_{2}\right)$ is obtained from the ratio between the settling time of frequency deviation in area $2\left(\varsigma_{s 2}\right)$ and power system time constant $\left(T_{p 2}\right)$ of area 2

$$
F R I_{2}=\frac{\varsigma_{s 2}}{T_{p 2}}
$$

Step 5.3; The Feasible Restoration Index $3\left(\varepsilon_{3}\right)$ is obtained from the ratio between the settling time of tie -line power deviation $\left(\varsigma_{s 3}\right)$ and synchronizing power coefficient $T_{12}$

$$
\mathrm{FRI}_{3}=\frac{\varsigma_{s 3}}{T_{12}}
$$

Step 5.4; The Feasible Restoration Index $4\left(\varepsilon_{4}\right)$ is obtained from the peak value of the frequency deviation $\Delta F_{1}\left(\varsigma_{p}\right)$ response of area 1 with respect to the final value $\Delta F_{1}\left(\varsigma_{s}\right)$

$$
F R I_{4}=\Delta F_{1}\left(\varsigma_{p}\right)-\Delta F_{1}\left(\varsigma_{s}\right)
$$

Step 5.5; The Feasible Restoration Index 5( $\left.\varepsilon_{5}\right)$ is obtained from the peak value of the frequency deviation $\Delta F_{2}\left(\varsigma_{p}\right)$ response of area 2 with respect to the final value $\Delta F_{2}\left(\varsigma_{s}\right)$

$$
F R I_{5}=\Delta F_{2}\left(\varsigma_{p}\right)-\Delta F_{2}\left(\varsigma_{s}\right)
$$

Step 5.6; The Feasible Restoration Index $6\left(\varepsilon_{6}\right)$ is obtained from the peak value of the tie-line power deviation $\Delta P_{\text {tie }}\left(\varsigma_{p}\right)$ response with respect to the final value $\Delta P_{\text {tie }}\left(\varsigma_{s}\right)$

$$
F R I_{6}=\Delta P_{t i e}\left(\varsigma_{p}\right)-\Delta P_{t i e}\left(\varsigma_{s}\right)
$$

Step 5.7; The Feasible Restoration Index $7\left(\varepsilon_{7}\right)$ is obtained from the rate of change of control input deviation requirement for area 1 using Lagrangian's Interpolation method [27].

$$
F R I_{7}=\frac{\Delta P_{c 1}}{\text { Time }}
$$

Step 5.8; The Feasible Restoration Index $5\left(\varepsilon_{8}\right)$ is obtained from the rate of change of control input deviation requirement for area 2 using Lagrangian's Interpolation method.

$$
F R I_{8}=\frac{\Delta P_{c 2}}{\text { Time }}
$$

Case 2: This case is also a Poolco based transaction on TAHTIPS where in the GENCOs in each area participate not equally in LFC and load demand is more than the GENCO in area 1 and the load demand change occurs only in area 1 . This 
condition is indicated in the column entries of the DPM matrix and sum of the column entries is more than unity.

Case 3: It may happen that a DISCO violates a contract by demanding more power than that specified in the contract and this excess power is not contracted to any of the GENCOs. This uncontracted power must be supplied by the GENCOs in the same area to the DISCO. It is represented as a local load of the area but not as the contract demand. Consider scenario-1 again with a modification that DISCO 1 demands 0.1 p.u MW of excess power i.e., $\Delta$ Puc, ${ }_{1}=0.1$ p.u $\mathrm{MW}$ and $\Delta \mathrm{Puc}_{2}=0.0$ p.u MW. The total load in area $1=$ Load of DISCO $1+$ Load of DISCO $2=\Delta \mathrm{PL}_{1}+\Delta \mathrm{Puc}_{1}+\Delta \mathrm{PL}_{2}=0.1+0.1+0.1=0.3$ p.u MW.

Case 4: This case is similar to Case 2 to with a modification that DISCO 3 demands 0.1 p.u MW of excess power i.e., $\Delta$ Puc, ${ }_{3}=0$ p.u MW and., $\Delta$ Puc $_{4}=0$ p.u MW. The total load in area 2 $=$ Load of DISCO 3+Load of DISCO $4=\Delta \mathrm{PL}_{1}+\Delta \mathrm{PL}_{2}+\Delta \mathrm{Puc}_{2}$ $=0+0.1+0=0.1$ p.u MW.

Case 5: In this case which is similar to Case 3 with a modification that DISCO 1 and DISCO 3 demands 0.1 p.u MW of excess power i.e., $\Delta$ Puc, ${ }_{1}=0.1$ p.u MW and $\Delta \mathrm{Puc}_{3}=0.1 \mathrm{p} . \mathrm{u}$ MW. The total load in area $1=$ Load of DISCO $1+$ Load of DISCO $2=\Delta \mathrm{PL}_{1}+\Delta \mathrm{Puc}_{1}+\Delta \mathrm{PL}_{2}=0.1+0.1+0.1=0.3$ and total demand in area $2=$ Load of DISCO $3+$ Load of DISCO 4 $=\Delta \mathrm{PL}_{3}+\Delta \mathrm{Puc}_{3}+\Delta \mathrm{PL}_{4}=0+0.1+0=0.1$ p.u MW

\subsubsection{Scenario 2: Bilateral transaction}

Case 6: Here all the DISCOs have contract with the GENCOs and the following DISCO Participation Matrix (DPM) be considered [25].

$D P M=\left[\begin{array}{cccc}0.5 & 0.25 & 0.5 & 0.4 \\ 0.2 & 0.25 & 0.2 & 0.2 \\ 0.0 & 0.3 & 0.2 & 0.25 \\ 0.3 & 0.2 & 0.1 & 0.15\end{array}\right]$

In this case, the DISCO 1, DISCO 2, DISCO 3 and DISCO 4, demands 0.15 p.u MW, $\quad 0.05$ p.u MW, 0.15 p.u MW and 0.05 p.u MW from GENCOs as defined by $c p f$ in the DPM matrix and each GENCO participates in LFC as defined by the following ACE participation factor $\operatorname{apf}_{11}=\operatorname{apf}_{12}=0.5$ and $\operatorname{apf}_{21}$ $=\operatorname{apf}_{22}=0.5$. The dynamic responses are shown in Fig. 5 . From this figure 5 the corresponding $F R I_{1}, F R I_{2}, F R I_{3}, F R I_{4}$ and $F R I_{5}$ are calculated.

Case 7: For this case also bilateral transaction on TAHTIPS is considered with a modification that the GENCOs in each area participate not equally in LFC and load demand is more than the GENCO in both the areas. But it is assumed that the load demand change occurs in both areas and the sum of the column entries of the DPM matrix is more than unity.
Case 8: Considering in the case 7 again with a modification that DISCO 1 demands 0.1 p.u MW of excess power i.e., $\Delta$ Puc ${ }_{1}=$ 0.1 p.u.MW and $\Delta \mathrm{Puc}_{2}=0.0$ p.u MW. The total load in area 1 $=$ Load of DISCO $1+$ Load of DISCO $2=\Delta \mathrm{PL}_{1}+\Delta \mathrm{Puc}_{1}+\Delta \mathrm{PL}_{2}$ $=0.15+0.1+0.05=0.3$ p.u MW and total load in area $2=$ Load of DISCO $3+$ Load of DISCO $4=\Delta \mathrm{PL}_{3}+\Delta \mathrm{PL}_{4}=0.15+0.05=0.2 \mathrm{p} . \mathrm{u}$ MW.

Case 9 In the case which similar to case 8 with a modification that DISCO 3 demands 0.1 p.u.MW of excess power i.e., $\Delta \mathrm{Puc}_{3}$ $=0.1$ p.u MW. The total load in area $1=$ Load of DISCO $1+$ Load of DISCO $2=\Delta \mathrm{PL}_{3}+\Delta \mathrm{PL}_{4}=0.15+0.05=0.2$ p.u.MW and total demand in area $2=$ Load of DISCO $3+$ Load of DISCO $4=\Delta \mathrm{PL}_{3}+\Delta \mathrm{PL}_{4}+\Delta \mathrm{Puc}_{3}=0.15+0.05+0.1=0.3$ p.u MW

Case 10: In the case which similar to case 9 with a modification that DISCO 1 and DISCO 3 demands 0.1 p.u MW of excess power i.e., $\Delta$ Puc, ${ }_{1}=0.1$ p.u MW and $\Delta \mathrm{Puc}_{3}=0.1$ p.u MW. The total load in area $1=$ Load of DISCO $1+$ Load of DISCO $2=$ $\Delta \mathrm{PL}_{1}+\Delta \mathrm{Puc}_{1}+\Delta \mathrm{PL}_{2}=0.15+0.1+0.05=0.3$ p.u MW and total load in area $2=$ Load of DISCO $3+$ Load of DISCO $4=\Delta \mathrm{PL}_{3}+$ $\Delta \mathrm{Puc}_{3}+\Delta \mathrm{PL}_{4}=0.15+0.1+0.05=0.3$ p.u MW. For the Cases 110 , the Feasible Restoration Indices are $F R I_{1}, F R I_{2}, F R I_{3}, F R I_{4}$, $F R I_{5}, F R I_{6}, F R I_{7}$ and $F R I_{8}$ or $\varepsilon_{1}, \varepsilon_{2}, \varepsilon_{3}, \varepsilon_{4}, \varepsilon_{5}, \varepsilon_{6}, \varepsilon_{7}$, and $\varepsilon_{8}$ are calculated are tabulated in Table 3 and Table 5.

\subsection{Comprehensive Restoration Indices}

Apart from the normal operating condition of the TAHTRIPS (with Mechanical/Electrical governor) few other case studies like one unit outage in an area, outage of one distributed generation in an area are considered individually. With the various case studies and based on their optimal gains the corresponding $\mathrm{CRI}$ is obtained as follows.

Case 11: In the TAHTIPS considering all the DISCOs have contract with the GENCOs but GENCO4 is outage in area-2. In this case, the DISCO 1, DISCO 2, DISCO 3 and DISCO 4, demands 0.15 p.u MW, 0.05 p.u MW, 0.15 pu.MW and 0.05 pu.MW from GENCOs as defined by $c p f$ in the DPM matrix (23). The output GENCO4 $=0.0$ p.u MW. The Comprehensive Restoration Indices

$$
\mathrm{CRI}_{1}, \mathrm{CRI}_{2}, \mathrm{CRI}_{3}, \mathrm{CRI}_{4}, \mathrm{CRI}_{5}, \mathrm{CRI}_{6}, \mathrm{CRI}_{7} \text { and } \mathrm{CRI}_{8} \text { ) are }
$$

obtained as $\varepsilon_{9}, \varepsilon_{10}, \varepsilon_{11}, \varepsilon_{12}, \varepsilon_{13}, \varepsilon_{14}, \varepsilon_{15}, \varepsilon_{16}$ and are tabulated in Table 6 .

Case 12: Consider in this case which is same as Case 11 but DISCO 1 demands 0.1 p.u MW of excess power i.e., $\Delta$ Puc $_{1}=0.1$ p.u.MW and $\Delta \mathrm{Puc}_{2}=0.0$ p.u MW. The total load in area $1=$ Load of DISCO $1+$ Load of DISCO $2=\Delta \mathrm{PL}_{1}+$ $\Delta \mathrm{Puc}_{1}+\Delta \mathrm{PL}_{2}=0.15+0.1+0.05=0.3$ p.u MW and total load in area $2=$ Load of DISCO $3+$ Load of DISCO $4=\Delta \mathrm{PL}_{3}+\Delta \mathrm{PL}_{4}$ $=0.15+0.05=0.2$ p.u MW

Case 13: This case is same as Case 11 with a modification that DISCO 3 demands 0.1 p.u MW of excess power i.e., $\Delta$ Puc ${ }_{3}=$ 0.1 p.u MW. The total load in area $1=$ Load of DISCO $1+$ Load of DISCO $2=\Delta \mathrm{PL}_{3}+\Delta \mathrm{PL}_{4}=0.15+0.05=0.2$ p.u MW and total demand in area $2=$ Load of DISCO $3+$ Load of DISCO $4=\Delta \mathrm{PL}_{3}$ $+\Delta \mathrm{PL}_{4}+\Delta \mathrm{Puc}_{3}=0.15+0.05+0.1=0.3$ p.u MW 
Case 14: In this case which is similar to Case 11 with a modification that DISCO 1 and DISCO 3 demands 0.1 p.u MW of excess power i.e., $\Delta$ Puc ${ }_{1}=0.1$ p.u.MW and $\Delta \mathrm{Puc}_{3}=0.1$ p.u MW. The total load in area $1=$ Load of DISCO $1+$ Load of DISCO $2=\Delta \mathrm{PL}_{1}+\Delta \mathrm{Puc}_{1}+\Delta \mathrm{PL}_{2}=0.15+0.1+0.05=0.3 \mathrm{p} . \mathrm{u}$ MW and total load in area $2=$ Load of DISCO $3+$ Load of DISCO $4=\Delta \mathrm{PL}_{3}+\Delta \mathrm{Puc}_{3}+\Delta \mathrm{PL}_{4}=0.15+0.1+0.05=0.3$ p.u MW. For the Case 11-14, the corresponding Comprehensive Restoration Indices

$C R I_{1}, C R I_{2}, C R I_{3}, C R I_{4}, C R I_{5}, C R I_{6}, C R I_{7}$ and $C R I_{8}$ are calculated and tabulated in Table 6

5.3 Power System Restoration Assessment

a) Based on Settling Time

(i) If $\varepsilon_{1}, \varepsilon_{2}, \varepsilon_{9}, \varepsilon_{10} \geq 1$ and $\varepsilon_{3}, \varepsilon_{11} \geq 50$ then more amount of distributed generation requirement is needed

b) Based on peak undershoot

(i) If $\varepsilon_{4}, \varepsilon_{5}, \varepsilon_{12}, \varepsilon_{13} \geq 1$ and $\varepsilon_{6}, \varepsilon_{14} \geq 0.15$ then the system is vulnerable and the system becomes unstable and may result to blackout.

(ii) If $0.5 \leq \varepsilon_{4}, \varepsilon_{5}, \varepsilon_{12}, \varepsilon_{13} \leq 1$ then more amount of distribution generation requirement is required but load shedding is also preferable.

(iii) If $0.05 \leq \varepsilon_{6}, \varepsilon_{14} \leq 0.15$ then the FACTS devices are required for the improvement of the tie-line power oscillations.

c) Based on control input deviation

(i) If $0.065 \leq \varepsilon_{7}, \varepsilon_{8}, \varepsilon_{15}, \varepsilon_{16} \leq 0.07$ then more amount of distributed generation is needed.

(ii) If $\varepsilon_{7}, \varepsilon_{8}, \varepsilon_{15}, \varepsilon_{16} \geq 0.07$ then more amount of distributed generation as well as load shedding is preferable.

Table 1 Optimized Controller parameters of the TAHTRIPS (with Mechanical Hydro governor)

\begin{tabular}{|c|c|c|c|c|}
\hline $\begin{array}{c}\text { TAHTRIPS } \\
\text { (with Mechanical } \\
\text { Hydro Governor) }\end{array}$ & \multicolumn{2}{|c|}{$\begin{array}{c}\text { Controller gain of } \\
\text { AREA 1 }\end{array}$} & $\begin{array}{c}\text { Controller gain of } \\
\text { AREA 2 }\end{array}$ \\
\cline { 2 - 5 } & $\mathrm{K}_{\mathrm{p} 1}$ & $\mathrm{~K}_{\mathrm{i} 1}$ & $\mathrm{~K}_{\mathrm{p} 2}$ & $\mathrm{~K}_{\mathrm{i} 2}$ \\
\hline Case 1 & 0.211 & 0.563 & 0.237 & 0.114 \\
\hline Case 2 & 0.234 & 0.312 & 0.245 & 0.169 \\
\hline Case 3 & 0.294 & 0.412 & 0.257 & 0.198 \\
\hline Case 4 & 0.256 & 0.456 & 0.312 & 0.201 \\
\hline Case 5 & 0.298 & 0.487 & 0.359 & 0.242 \\
\hline Case 6 & 0.264 & 0.412 & 0.215 & 0.169 \\
\hline Case 7 & 0.305 & 0.427 & 0.236 & 0.184 \\
\hline Case 8 & 0.317 & 0.485 & 0.218 & 0.171 \\
\hline Case 9 & 0.278 & 0.424 & 0.285 & 0.195 \\
\hline Case 10 & 0.347 & 0.489 & 0.244 & 0.187 \\
\hline Case 11 & 0.384 & 0.348 & 0.188 & 0.175 \\
\hline Case 12 & 0.401 & 0.351 & 0.215 & 0.205 \\
\hline Case 13 & 0.392 & 0.363 & 0.241 & 0.237 \\
\hline Case 14 & 0.412 & 0.385 & 0.278 & 0.244 \\
\hline
\end{tabular}

Table 2 Optimized Controller parameters of the TAHTRIPS (with Electric Hydro governor)

\begin{tabular}{|c|c|c|c|c|}
\hline $\begin{array}{c}\text { TAHTRIPS } \\
\text { (with Electric } \\
\begin{array}{c}\text { Hydro } \\
\text { Governor) }\end{array}\end{array}$ & $\begin{array}{c}\text { Controller gain of } \\
\text { AREA 1 }\end{array}$ & $\begin{array}{c}\text { Controller gain of } \\
\text { AREA 2 }\end{array}$ \\
\cline { 2 - 5 } & $\mathrm{K}_{\mathrm{p} 1}$ & $\mathrm{~K}_{\mathrm{i} 1}$ & $\mathrm{~K}_{\mathrm{p} 2}$ & $\mathrm{~K}_{\mathrm{i} 2}$ \\
\hline Case 1 & 0.082 & 0.162 & 0.192 & 0.077 \\
\hline Case 2 & 0.101 & 0.174 & 0.202 & 0.089 \\
\hline Case 3 & 0.117 & 0.196 & 0.197 & 0.083 \\
\hline Case 4 & 0.095 & 0.169 & 0.212 & 0.101 \\
\hline Case 5 & 0.126 & 0.212 & 0.218 & 0.104 \\
\hline Case 6 & 0.015 & 0.226 & 0.118 & 0.124 \\
\hline Case 7 & 0.305 & 0.427 & 0.236 & 0.184 \\
\hline Case 8 & 0.317 & 0.485 & 0.218 & 0.171 \\
\hline Case 9 & 0.278 & 0.424 & 0.285 & 0.195 \\
\hline Case 10 & 0.347 & 0.489 & 0.244 & 0.187 \\
\hline Case 11 & 0.395 & 0.227 & 0.282 & 0.162 \\
\hline Case 12 & 0.401 & 0.251 & 0.215 & 0.175 \\
\hline Case 13 & 0.392 & 0.263 & 0.221 & 0.137 \\
\hline Case 14 & 0.412 & 0.285 & 0.258 & 0.144 \\
\hline
\end{tabular}

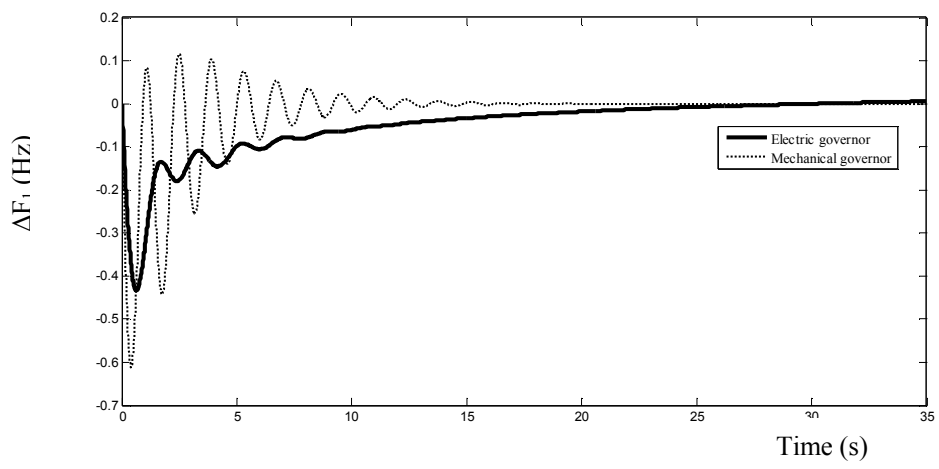

Fig.4 (a) $\Delta \mathrm{F}_{1}(\mathrm{~Hz}) \mathrm{Vs}$ Time (s)

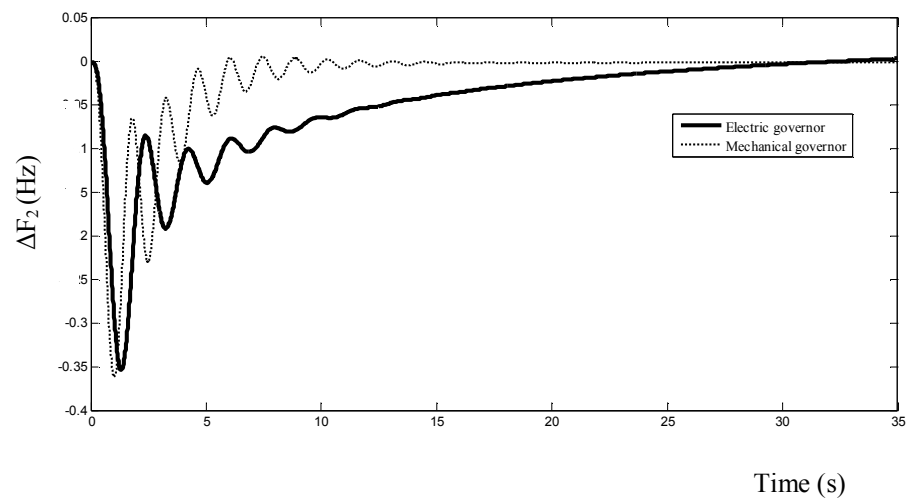

Fig.4 (b) $\Delta \mathrm{F}_{2}(\mathrm{~Hz}) \mathrm{Vs}$ Time (s) 


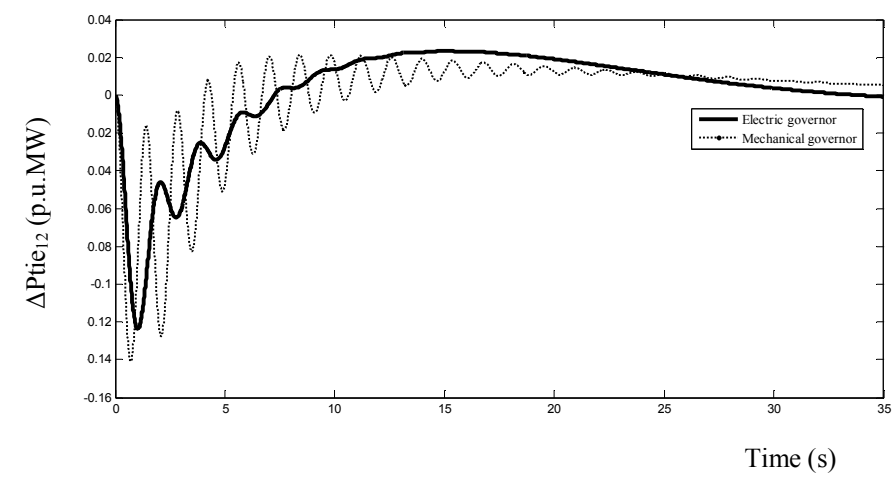

Fig.4 (c) $\Delta$ Ptie $_{12}$ (p.u.MW) Vs Time (s)

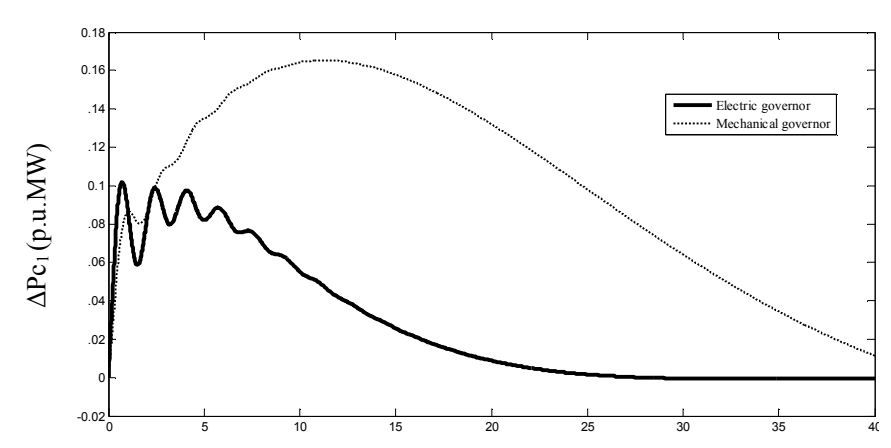

Fig.4 (d) $\Delta \mathrm{Pc}_{1}$ (p.u.MW) Vs Time (s)

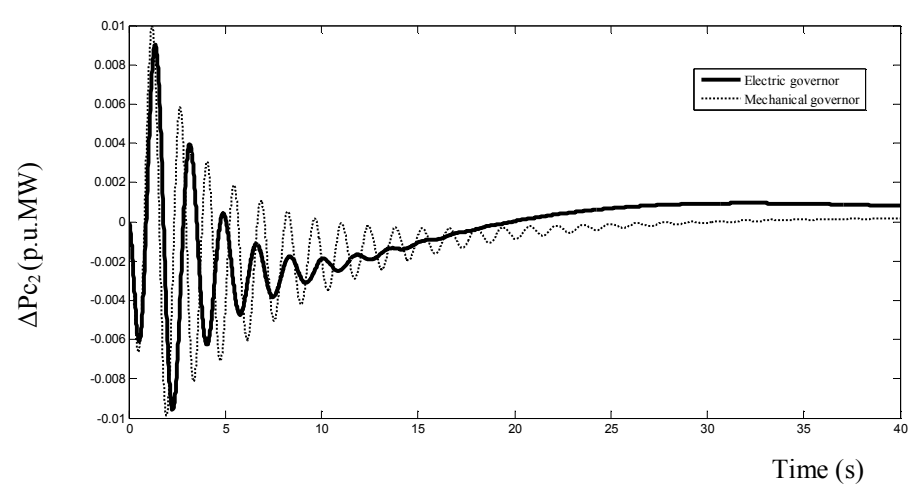

Fig.4 (e) $\Delta \mathrm{Pc}_{2}$ (p.u.MW) Vs Time (s)

Fig.4 Dynamic responses of the frequency deviations, tie- line power deviations and Control input deviations for a two-area hydro-thermal LFC system in the restructured scenario-1 (poolco based transactions

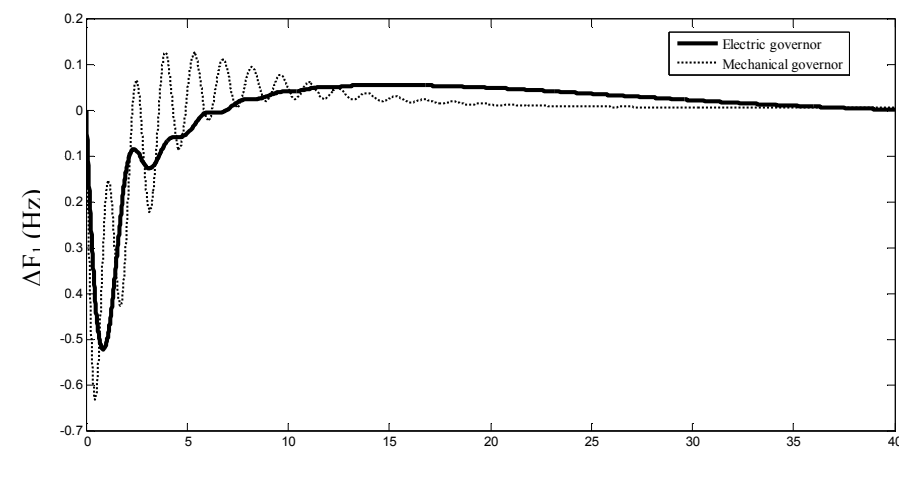

Fig.5 (a) $\Delta \mathrm{F}_{1}(\mathrm{~Hz}) \mathrm{Vs}$ Time (s) Time (s)

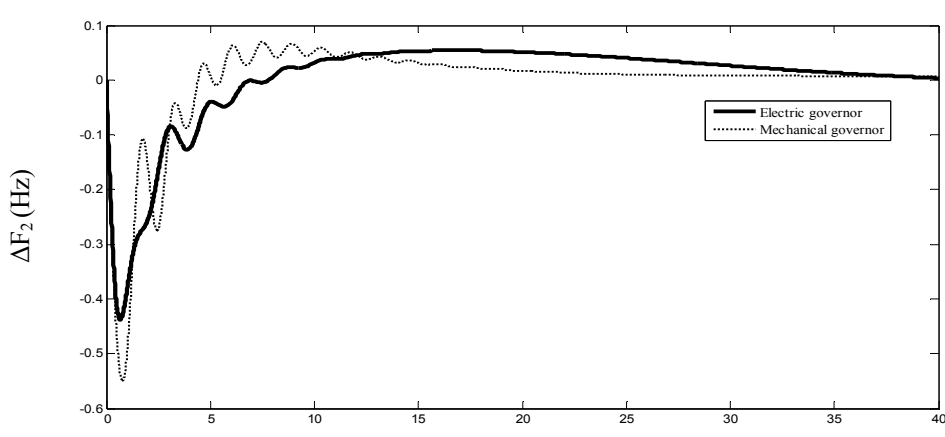

Time (s)

Fig.5 (b) $\Delta \mathrm{F}_{2}(\mathrm{~Hz})$ Vs Time (s)

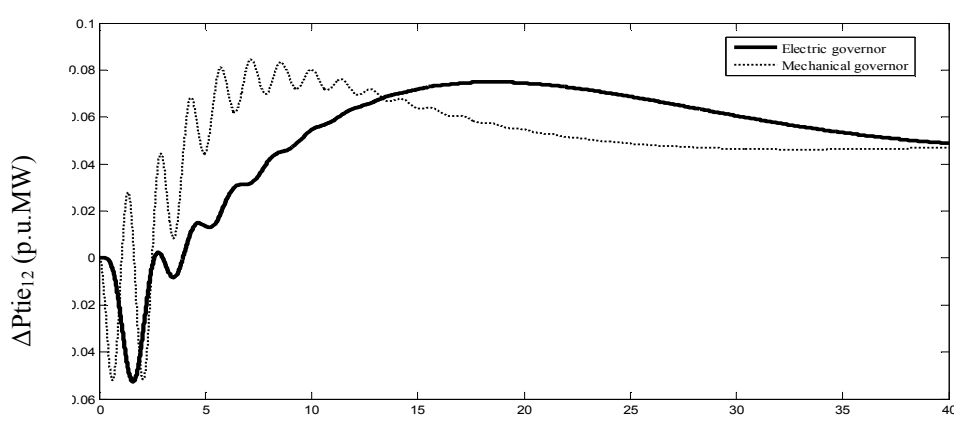

Fig.5 (c) $\Delta$ Ptie $_{12, \text { actual }}$ (p.u.MW) Vs Time (s)

Time (s)

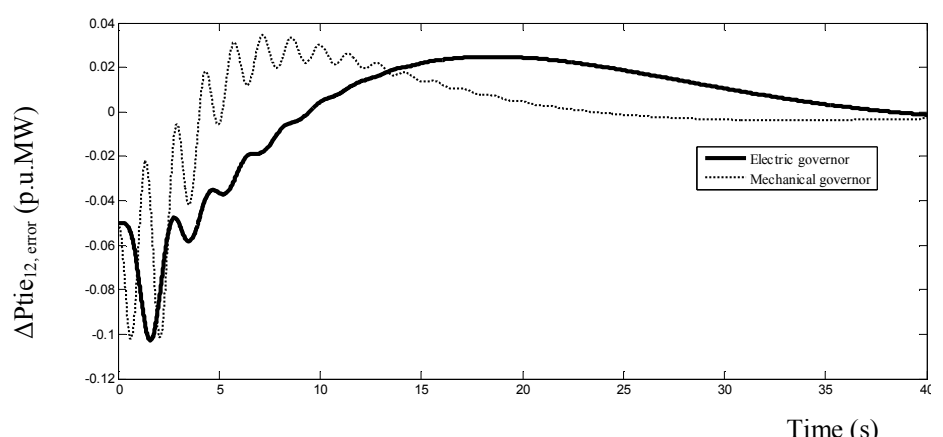

Fig.5 (d) $\Delta$ Ptie $_{12, \text { error (p.u.MW) Vs Time (s) }}$ 


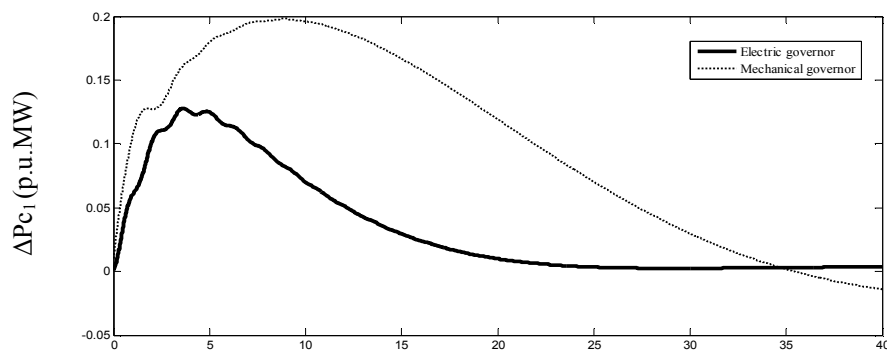

Fig.5 (e) $\Delta \mathrm{Pc}_{1}$ (p.u.MW) Vs Time (s)

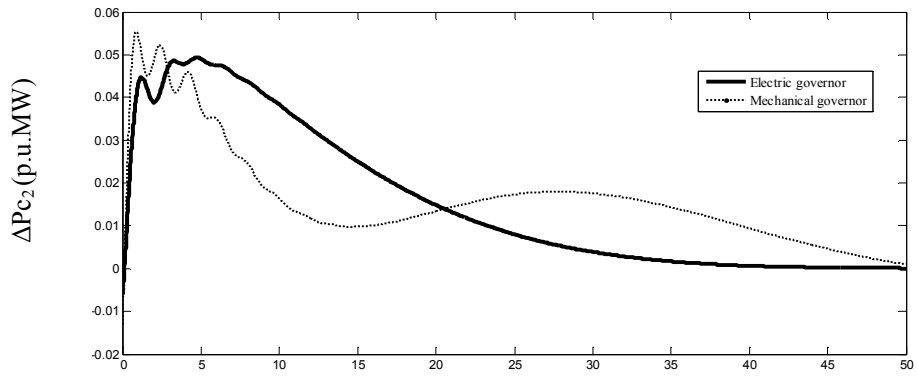

Time (s)

Fig.5 (f) $\Delta \mathrm{Pc}_{2}$ (p.u.MW) Vs Time (s)

Fig.5 Dynamic responses of the frequency deviations, tie- line power deviations, and Control input deviations for a two area HT system in the restructured scenario-2 (bilateral based transactions)

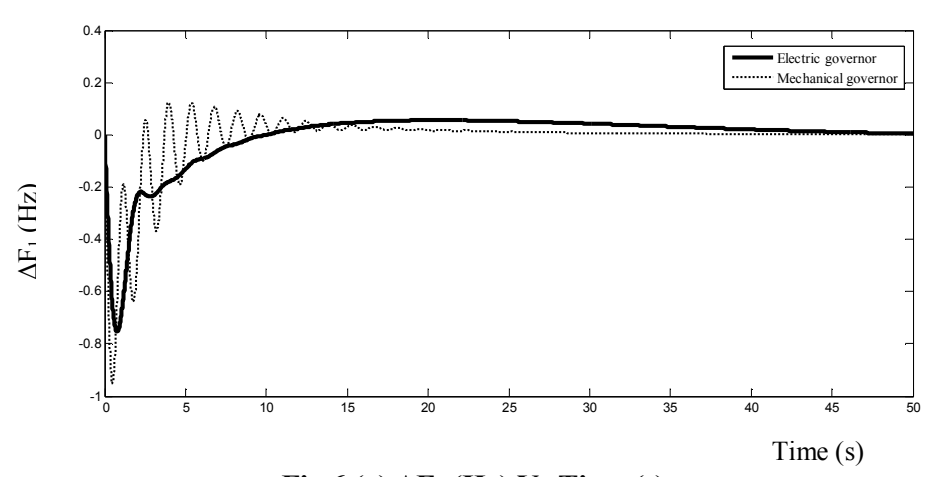

Fig.6 (a) $\Delta \mathrm{F}_{1}(\mathrm{~Hz}) \mathrm{Vs}$ Time (s)

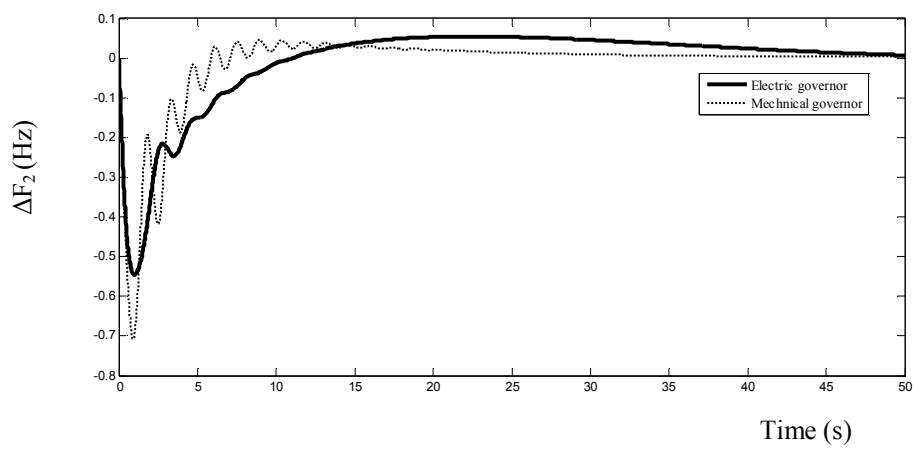

Fig.6 (b) $\Delta F_{2}(H z)$ Vs Time (s)

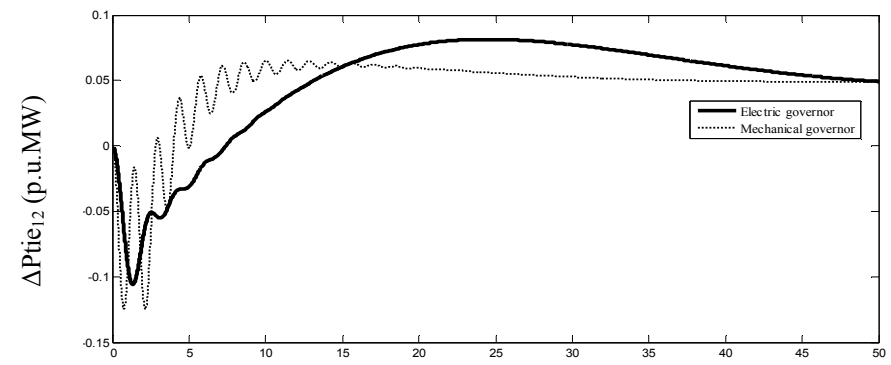

Fig.6 (c) $\Delta$ Ptie $_{12, \text { actual }}$ (p.u.MW) Vs Time (s)

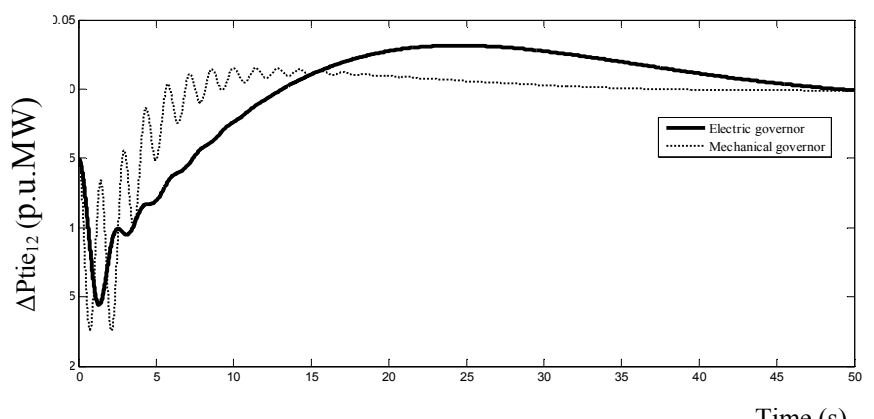

Fig.6 (d) $\Delta$ Ptie $_{12, \text { error (p.u.MW) Vs Time (s) }}$

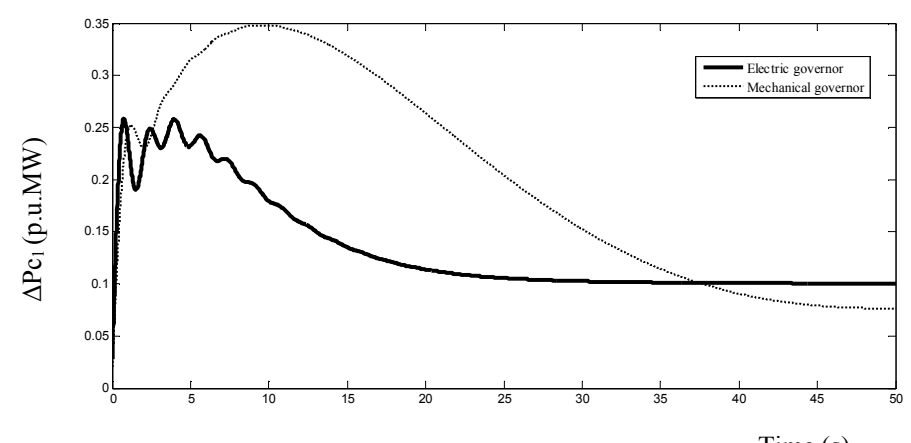

Fig.6 (e) $\Delta P c_{1}$ (p.u.MW) Vs Time (s)

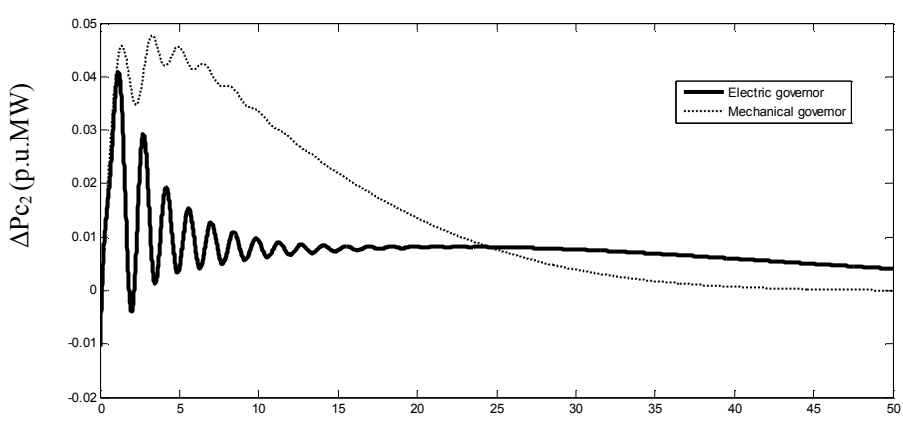

Fig.6 (f) $\Delta \mathrm{Pc}_{2}$ (p.u.MW) Vs Time (s)

Time (s)

Fig.6 Dynamic responses of the frequency deviations, tie- line power deviations and the Control input deviations for a two area HT system in the restructured scenario-3 (Contract violation) 
Table 3 Feasible Restoration Indices on TAHTRIPS (with Mechanical Hydro governor)

\begin{tabular}{|c|c|c|c|c|c|c|c|c|}
\hline $\begin{array}{c}\text { TAHTRIPS } \\
\text { (with Mechanical } \\
\text { Hydro governor) }\end{array}$ & \multicolumn{3}{|c|}{$\begin{array}{c}\text { Feasible Restoration } \\
\text { Indices (FRI) based on } \\
\text { Settling time }\left(\varsigma_{s}\right)\end{array}$} & $\begin{array}{c}\text { Feasible Restoration } \\
\text { Indices (FRI) based on } \\
\text { Peak over/ under shoot } \\
\end{array}$ & \multicolumn{3}{|c|}{$\left.M_{p}\right)$} & $\begin{array}{c}\text { Feasible Restoration } \\
\text { Indices (FRI) based } \\
\text { on } \\
\text { control input } \\
\text { deviation }\left(\Delta P_{c}\right)\end{array}$ \\
\cline { 2 - 11 } & $\varepsilon_{1}$ & $\varepsilon_{2}$ & $\varepsilon_{3}$ & $\varepsilon_{4}$ & $\varepsilon_{5}$ & $\varepsilon_{6}$ & $\varepsilon_{7}$ & $\varepsilon_{8}$ \\
\hline Case 1 & 0.975 & 0.945 & 45.96 & 0.431 & 0.351 & 0.125 & 0.051 & --- \\
\hline Case 2 & 1.006 & 1.007 & 56.23 & 0.499 & 0.412 & 0.148 & 0.068 & --- \\
\hline Case 3 & 1.425 & 1.234 & 55.51 & 0.952 & 0.583 & 0.141 & 0.071 & \\
\hline Case 4 & 1.275 & 1.359 & 56.23 & 0.632 & 0.619 & 0.155 & 0.067 & 0.065 \\
\hline Case 5 & 1.512 & 1.475 & 59.63 & 0.985 & 0.712 & 0.159 & 0.069 & 0.066 \\
\hline Case 6 & 0.915 & 0.889 & 46.78 & 0.624 & 0.556 & 0.055 & 0.057 & 0.067 \\
\hline Case 7 & 1.624 & 1.322 & 48.69 & 0.883 & 0.654 & 0.069 & 0.064 & 0.062 \\
\hline Case 8 & 1.525 & 1.425 & 55.96 & 0.958 & 0.723 & 0.012 & 0.063 & 0.069 \\
\hline Case 9 & 1.278 & 1.534 & 55.51 & 0.952 & 0.883 & 0.021 & 0.071 & 0.074 \\
\hline Case 10 & 1.447 & 1.425 & 52.29 & 1.012 & 0.998 & 0.095 & 0.078 & 0.058 \\
\hline
\end{tabular}

Table 4 Comprehensive Restoration Indices on TAHTRIPS (with Mechanical Hydro governor)

\begin{tabular}{|c|c|c|c|c|c|c|c|c|}
\hline $\begin{array}{c}\text { TAHTRIPS } \\
\text { (with Mechanical } \\
\text { Hydro governor) }\end{array}$ & \multicolumn{3}{|c|}{$\begin{array}{c}\text { Comprehensive } \\
\text { Restoration } \\
\text { Indices (CRI) based on } \\
\text { Settling time }\left(s_{s}\right)\end{array}$} & $\begin{array}{c}\text { Comprehensive } \\
\text { Restoration Indices } \\
\text { (CRI) based on Peak } \\
\text { over/ under shoot } \\
\left(M_{p}\right)\end{array}$ & $\begin{array}{c}\text { Restoration Indices } \\
\text { Comprehensive } \\
\text { RI) based on } \\
\text { control input } \\
\text { deviation }\left(\Delta P_{c}\right)\end{array}$ \\
\cline { 2 - 10 } & $\varepsilon_{9}$ & $\varepsilon_{10}$ & $\varepsilon_{11}$ & $\varepsilon_{12}$ & $\varepsilon_{13}$ & $\varepsilon_{14}$ & $\varepsilon_{15}$ & $\varepsilon_{16}$ \\
\hline Case 11 & 1.625 & 1.537 & 55.48 & 0.795 & 0.729 & 0.158 & 0.085 & 0.061 \\
\hline Case 12 & 1.724 & 1.637 & 56.39 & 0.895 & 0.621 & 0.162 & 0.091 & 0.041 \\
\hline Case 13 & 1.625 & 1.817 & 59.36 & 0.905 & 0.929 & 0.164 & 0.095 & 0.051 \\
\hline Case 14 & 1.947 & 1.825 & 59.29 & 1.012 & 1.128 & 0.169 & 0.111 & 0.058 \\
\hline
\end{tabular}

Table 5 Feasible Restoration Indices on TAHTRIPS (with Electric Hydro governor)

\begin{tabular}{|c|c|c|c|c|c|c|c|c|}
\hline $\begin{array}{c}\text { TAHTRIPS } \\
\text { (with Electric Hydro } \\
\text { governor) }\end{array}$ & \multicolumn{3}{|c|}{$\begin{array}{c}\text { Feasible Restoration } \\
\text { Indices (FRI) based on } \\
\text { Settling time }\left(\varsigma_{s}\right)\end{array}$} & $\begin{array}{c}\text { Feasible Restoration } \\
\text { Indices (FRI) based on } \\
\text { Peak over/ under shoot } \\
\left(M_{p}\right)\end{array}$ & $\begin{array}{c}\text { Feasible Restoration } \\
\text { Indices (FRI) based } \\
\text { on } \\
\text { control input } \\
\text { deviation }\left(\Delta P_{c}\right)\end{array}$ \\
\cline { 2 - 11 } & $\varepsilon_{1}$ & $\varepsilon_{2}$ & $\varepsilon_{3}$ & $\varepsilon_{4}$ & $\varepsilon_{5}$ & $\varepsilon_{6}$ & $\varepsilon_{7}$ & $\varepsilon_{8}$ \\
\hline Case 1 & 0.906 & 0.942 & 42.96 & 0.418 & 0.317 & 0.091 & 0.051 & --- \\
\hline Case 2 & 1.017 & 0.956 & 49.23 & 0.429 & 0.382 & 0.132 & 0.059 & --- \\
\hline Case 3 & 1.315 & 1.142 & 53.12 & 0.852 & 0.483 & 0.135 & 0.068 & \\
\hline Case 4 & 1.255 & 1.265 & 54.27 & 0.512 & 0.519 & 0.145 & 0.063 & 0.065 \\
\hline Case 5 & 1.422 & 1.386 & 55.28 & 0.885 & 0.612 & 0.147 & 0.074 & 0.066 \\
\hline Case 6 & 0.915 & 0.889 & 46.78 & 0.624 & 0.556 & 0.055 & 0.057 & 0.067 \\
\hline Case 7 & 1.524 & 1.212 & 48.69 & 0.763 & 0.611 & 0.061 & 0.061 & 0.060 \\
\hline Case 8 & 1.695 & 1.345 & 52.96 & 0.848 & 0.623 & 0.012 & 0.061 & 0.062 \\
\hline Case 9 & 1.168 & 1.434 & 53.51 & 0.862 & 0.783 & 0.011 & 0.069 & 0.071 \\
\hline Case 10 & 1.337 & 1.515 & 58.29 & 0.998 & 0.898 & 0.095 & 0.070 & 0.064 \\
\hline
\end{tabular}


Table 6 Comprehensive Restoration Indices on TAHTRIPS (with Electric Hydro governor)

\begin{tabular}{|c|c|c|c|c|c|c|c|c|}
\hline \multirow[t]{2}{*}{$\begin{array}{c}\text { TAHTRIPS } \\
\text { (with Electric } \\
\text { Hydro governor) }\end{array}$} & \multicolumn{3}{|c|}{$\begin{array}{c}\text { Comprehensive } \\
\text { Restoration } \\
\text { Indices }(\mathrm{CRI}) \text { based on } \\
\text { Settling time }\left(\varsigma_{s}\right)\end{array}$} & \multicolumn{3}{|c|}{$\begin{array}{c}\text { Comprehensive } \\
\text { Restoration Indices } \\
\text { (CRI) based on Peak } \\
\text { over/ under shoot } \\
\left(M_{p}\right)\end{array}$} & \multicolumn{2}{|c|}{$\begin{array}{l}\text { Comprehensive } \\
\text { Restoration Indices } \\
\text { (CRI) based on } \\
\text { control input } \\
\text { deviation }\left(\Delta P_{c}\right)\end{array}$} \\
\hline & $\varepsilon_{9}$ & $\varepsilon_{10}$ & $\varepsilon_{11}$ & $\varepsilon_{12}$ & $\varepsilon_{13}$ & $\varepsilon_{14}$ & $\varepsilon_{15}$ & $\varepsilon_{16}$ \\
\hline Case 11 & 1.525 & 1.417 & 54.36 & 0.665 & 0.719 & 0.148 & 0.075 & 0.055 \\
\hline Case 12 & 1.624 & 1.532 & 55.42 & 0.781 & 0.611 & 0.152 & 0.081 & 0.048 \\
\hline Case 13 & 1.525 & 1.711 & 58.16 & 0.813 & 0.939 & 0.154 & 0.089 & 0.048 \\
\hline Case 14 & 1.847 & 1.725 & 59.24 & 1.002 & 1.238 & 0.159 & 0.108 & 0.049 \\
\hline
\end{tabular}

\section{CONCLUSIONS}

This paper proposes the design of various Restoration Assessment Indices which highlights the necessary requirements to be adopted in minimizing the frequency deviations, tie-line power deviation in a two-area interconnected Hydro-Thermal restructured power system to ensure the reliable operation of the power system. The PI controllers are designed using BFO algorithm and implemented in a Two-Area Two-Unit HydroThermal Interconnected Restructured Power System without and with outraged conditions. The closed loop system was simulated and comparative studies of the output responses of the system for different type transactions conditions have been presented. From the simulated results it is observed that the restoration indices calculated for the Hydro Power Plants indicates that the Hydro plant with mechanical governor requires more sophisticated control for a better restoration of the power system output responses and to ensure improved Power System Restoration Assessment Indices (PSRAI) in order to provide good margin of stability than that of the Hydro plant with electric governor.

\section{ACKNOWLEDGMENTS}

The authors wish to thank the authorities of Annamalai University, Annamalainagar, Tamilnadu, India for the facilities provided to prepare this paper.

\section{APPENDIX}

\section{A. Data for Thermal Reheat Power System [25]}

Rating of each area $=2000 \mathrm{MW}$, Base power $=2000 \mathrm{MVA}$, $\mathrm{f}^{\mathrm{o}}=60 \mathrm{~Hz}, \mathrm{R}_{1}=\mathrm{R}_{2}=\mathrm{R}_{3}=\mathrm{R}_{4}=2.4 \mathrm{~Hz} /$ p.u. $\mathrm{MW}, \mathrm{T}_{\mathrm{g} 1}=\mathrm{T}_{\mathrm{g} 2}=$ $\mathrm{T}_{\mathrm{g} 3}=\mathrm{T}_{\mathrm{g} 4}=0.08 \mathrm{sec}, \mathrm{T}_{\mathrm{r} 1}=\mathrm{T}_{\mathrm{r} 2}=\mathrm{T}_{\mathrm{r} 1}=\mathrm{T}_{\mathrm{r} 2}=10 \mathrm{sec}, \mathrm{T}_{\mathrm{t} 1}=\mathrm{T}_{\mathrm{t} 2}$ $=\mathrm{T}_{\mathrm{t} 3}=\mathrm{T}_{\mathrm{t} 4}=0.3 \mathrm{sec}, \mathrm{K}_{\mathrm{p} 1}=\mathrm{K}_{\mathrm{p} 2}=120 \mathrm{~Hz} /$ p.u.MW, $\mathrm{T}_{\mathrm{p} 1}=\mathrm{T}_{\mathrm{p} 2}=$ $20 \mathrm{sec}, \beta_{1}=\beta_{2}=0.425$ p.u.MW $/ \mathrm{Hz}, \quad \mathrm{K}_{\mathrm{rl}}=\mathrm{K}_{\mathrm{r} 2}=\mathrm{K}_{\mathrm{r} 3}=\mathrm{K}_{\mathrm{r} 4}=$ $0.5,2 \pi T_{12}=0.545$ p.u.MW $/ \mathrm{Hz}, \mathrm{a}_{12}=-1, \Delta \mathrm{P}_{\mathrm{D} 1}=0.01$ p.u.MW

B. Data for Hydropower system with Mechanical governor [18]

$$
\mathrm{T}_{\mathrm{w}}=1, \mathrm{a}_{12}=-1 ; \mathrm{T}_{1}=48.7, \mathrm{~T}_{2}=0.513, \operatorname{Tr}=5
$$

C. Data for Hydro power system with Electric governor [19]

$$
\mathrm{K}_{\mathrm{d}}=4, \mathrm{~T}_{\mathrm{w}}=1 \mathrm{~s}, \mathrm{~K}_{\mathrm{p}}=1, \mathrm{~K}_{\mathrm{i}}=5
$$

\section{REFERENCES}

[1] V.Donde, M.A.Pai, I.A.Hiskens, "Simulation and Optimization in an AGC System after Deregulation", IEEE Transaction on Power System, 16(3), (2001), 481-489.

[2] F.Liu, Y.H.Song, J.Ma, S.Mei, Q.Lu, "Optimal loadFrequency control in restructured power systems", IEE proceeding on Generation Transmission and Distribution, 150(1), (2003), 87-95.

[3] A.Demiroren, H.L.Zeynelgil, "GA application to optimization of AGC in three-area power system after deregulation", Electrical Power and Energy System, 29(3), (2007), 230-240.

[4] H. Shayeghi, H.A. Shayanfar, O.P.Malik, Robust Decentralized Neural Networks Based LFC in a Deregulated Power System, Electric Power System Research, 77,(2007), 241-251.

[5] H. Shayeghi, H.A. Shayanfar, A. Jalili, "Load frequency Control Strategies: A state-of-the-art survey for the researcher", Energy Conversion and Management, 50(2), (2009), 344-353.

[6] Ibraheem, P. Kumar, D.P.Kothari, "Recent philosophies of automatic generation control strategies in power systems", IEEE Transactions on Power Systems, 20(1), (2005), 346357.

[7] M.M.Adibi, J.N. Borkoski, R.J.Kafka and T.L. Volkmann,” Frequency Response of Prime Movers during Restoration”, IEEE Transactions on Power Systems 14(2), (1999), 751756.

[8] M.M.Adibi and R.J.Kafka, "Power System Restoration Issues", IEEE Computer Applications in Power, 4(2), (1991), 19-24.

[9] Herman B. Ross, Ning Zhu, Jay Giri and Barbara Kindel, "An AGC Implementation for System Islanding and Restoration conditions", IEEE Transactions on Power Systems, 9(3), (1994), 1399-1410. 
[10] Jayesh J. Joglekar and Yogesh P. Nerkar, "A different approach in system restoration with special consideration of Islanding schemes", Electrical Power and Energy Systems, 30, (2008), 519-524.

[11] CH. Liang, C.Y.Chung, K.P.Wong, X.Z.Duan, C.T.Tse, Study of Differential Evolution for Optimal Reactive Power Dispatch, IET Transactions on Generation Transmission and Distribution, 1(2007), 253-260.

[12] Y.Shi, R.C.Eberhart, Parameter Selection in PSO, "In Proceedings of $7^{\text {th }}$ Annual Conference on Evolutionary Computation", (1998), 591-601.

[13] M.Dorigo, M.Birattari, T.Stutzle, “Ant Colony optimization: artificial ants as a computational intelligence technique", IEEE. Computational Intelligence Magazine, (2007), 28-39

[14] Ghoshal, "Application of GA/GA-SA based fuzzy automatic control of multi-area thermal generating system", Electric Power System Research, 70, (2004), 115-127.

[15] M.A.Abido, "Optimal design of power system stabilizers using particle swarm optimization", IEEE Transaction. Energy Conversion, 17(3), (2002), 406-413.

[16] K.M.Passino, "Biomimicry of bacterial foraging for distributed optimization and control", IEEE Control Syst Magazine, 22 (3), (2002), 52-67.

[17] M.L. Kothari, B.L.Kaul and J.Nanda, "Automatic generation control of hydro-thermal system", Journal of Institution of Engineers (India), 61, (1980), 1-4

[18] Prabhat Kumar, K.E. Hole and R.P. Aggarwal, "Design of a decentralized AGC regulation for two-area hydro-thermal power system", Journal of Institution of Engineers (India), Vol.63, pt EL., pp.304-309, 1983

[19] O.P.Malik, G.S. Hope, S.C. Tripathy and N.Mital, "Decentralized sub-optimal load-frequency control of a hydro-thermal power system using state variable model", Electric power system research, Vol.8, pp.237-247, 1984/85.

[20] Nanda J, Mangala, A, Suri, S, "Some new findings on automatic generation control of an interconnected hydrothermal system with conventional controllers", IEEE Transactions of Energy Conversion, Vol.21,pp.187-194, March 2006

[21] Surya Prakash, S.K.Sinha, "Application of artificial intelligence in load frequency control of interconnected power system", International Journal of Engineering, Science and Technology, Vol.3, No.4, pp.264-275, 2011

[22] Janardan Nanda, Mishra.S., Lalit Chandra Saikia, "Maiden Application of Bacterial Foraging-Based optimization technique in multi-area Automatic Generation Control", IEEE Transaction on Power System, 24(2), (2009), 602609.

[23] S.Farook, P.Sangameswara Raju, "AGC controllers to optimize LFC regulation in deregulated powersystem", International Journal of Advances in Engineering \& Technology, IJAET ISSN:2231-1963, Nov 2011, Vol.1, Issue 5, pp. 278-289.
[24] C.Srinivasa Rao, "Implementation of Load Frequency Control of Hydrothermal System under Restructed Scenario Employing Fuzzy Controlled Genetic Algorithm", International Journal of Advanced Research in Electrical Electronics and Instrumentation Engineering, ISSN: 22788875,July 2012, Vol.1, Issue 1, pp.1-6.

[25] B.Paramasivam and I.A.Chidambaram, "Bacterial Foraging Optimization Based Load-Frequency Control of Interconnected Power Systems with Static Synchronous Series Compensator", International Journal of Latest Trend in Computing, Vol 1, Issue 2, pp.7-15, 2010.

[26] K.Ogatta, Modern Control System Engineering, $5^{\text {th }}$ Edition, Pearson Education, New Jessey, 2010.

[27] M.Shanthakumar, Computer Based Numerical Analysis, Khanna Publishers, New Delhi, 1999.

\section{AUTHORS' PROFILE}

R.Thirunavukarasu (1977) received Bachelor of Engineering in Electrical and Electronics Engineering (2001),Madurai kamaraj university Madurai, Master of engineering in power system (2004) from Annamalai university, Annamalainagar, Chidambaram. currently working as an Assistant professor in the department of electrical engineering, Annamalai university since 2007. He is currently working towards the Ph.D degree. His research interest are power system operation and Control, Electrical Measurements.

B.Paramasivam (1976) received Bachelor of Engineering in Electrical and Electronics Engineering (2002), Master of Engineering in Power System Engineering (2008) and he is working as Assistant Professor in the Department of Electrical Engineering, Annamalai University, Annamalainagar-608002, Tamilnadu, India. He is currently pursuing Ph.D degree in Electrical Engineering at Annamalai University, Annamalainagar. His research interests are in Power System, Control Systems, Electrical Measurements.

I.A.Chidambaram (1966) received Bachelor of Engineering in Electrical and Electronics Engineering (1987), Master of Engineering in Power System Engineering (1992) and Ph.D in Electrical Engineering (2007) from Annamalai University, Annamalainagar. During 1988 - 1993 he was working as Lecturer in the Department of Electrical Engineering, Annamalai University and from 2007 he is working as Professor in the Department of Electrical Engineering, Annamalai University, Annamalainagar, Tamilnadu, India. He is a member of ISTE and ISCA. His research interests are in Power Systems, Electrical Measurements and Controls. 